\title{
Why do people prefer gratitude journaling over gratitude letters? The influence of individual differences in motivation and personality on web-based interventions
}

\author{
Lukasz D. Kaczmarek $^{\text {a,* }}$, Todd B. Kashdan ${ }^{\mathrm{b}}$, Dariusz Drążkowski ${ }^{a}$, Jolanta Enko ${ }^{a}$, Michał Kosakowski ${ }^{\mathrm{a}}$, \\ Agata Szäefer ${ }^{\mathrm{a}}$, Aleksandra Bujacz ${ }^{\text {a }}$ \\ ${ }^{a}$ Adam Mickiewicz University, Poland \\ ${ }^{\mathrm{b}}$ George Mason University, USA
}

\section{A R T I C L E I N F O}

\section{Article history:}

Received 5 February 2014

Received in revised form 30 October 2014

Accepted 2 November 2014

\section{Keywords:}

Gratitude

Motivation

Positive psychology

\begin{abstract}
A B S T R A C T
Gratitude interventions can be divided into those that explicitly cultivate appreciative feelings (gratitude journaling) and those that strengthen relationships (gratitude letter). There is an absence of research on the motivation to participate in different gratitude interventions. Using an experimental approach, we compared two gratitude interventions on underlying motivations for starting and completion. We provided students $(N=904)$ with an opportunity to start a web-based intervention (gratitude journaling or letter). Subsequently, we measured the perceived usefulness of the intervention, social norms related to using this intervention, their self-control, and intention to start the intervention. Results showed that keeping a gratitude journal and writing a gratitude letter to someone were perceived as equally useful and socially acceptable. Yet participants felt less efficacious in writing a gratitude letter, which in turn decreased self-initiation and the actual completion of the intervention. As for individual differences, people with greater dispositional gratitude expected the intervention to be easier, more beneficial, and socially acceptable; meaningful sex differences also emerged. Our findings provide new insights into underlying motivations and individual differences that influence the initiation and efficacy of gratitude interventions.
\end{abstract}

(c) 2014 Elsevier Ltd. All rights reserved.

\section{Introduction}

Expressing gratitude to another person via a letter offers a unique vehicle for furthering one's own gratitude (Toepfer \& Walker, 2009) and enhancing social relationships (Lambert, Clark, Durtschi, Fincham, \& Graham, 2010; Lambert \& Fincham, 2011). Yet, when introduced to a variety of positive psychological interventions, people rarely show a preference to write gratitude letters to benefactors. In a recent study on self-initiated interventions, people were five times more likely to keep a journal about people, objects, and events that produced gratitude than use emails, texts, or phone calls to express gratitude to someone (Parks, Della Porta, Pierce, Zilca, \& Lyubomirsky, 2012). To further understand the preference for and efficacy of gratitude interventions, we explored why people may prefer gratitude journaling over the expression of

* Corresponding author at: Adam Mickiewicz University in Poznań, Institute of Psychology, 89 Szamarzewskiego Street, PL-60-568 Poznan, Poland. Tel.: +48 61829 23 07; fax: +48 618292107.

E-mail address: Lkacz@amu.edu.pl (L.D. Kaczmarek). gratitude to specific benefactors. This is an important line of inquiry as theorists suggest that people will gain more from an intervention if there is congruence with their values/interests/preferences (Lyubomirsky \& Layous, 2013; Sheldon \& Lyubomirsky, 2007). As a secondary aim, we investigated the role of grateful dispositions (McCullough, Emmons, \& Tsang, 2002), and sex (Kaczmarek, Goodman, et al., 2014; Kaczmarek, Kashdan, et al., 2014) as individual differences that influence motivation towards the self-initiation of gratitude-related interventions.

\subsection{Perspectives on gratitude}

Gratitude stems from the recognition that one has obtained a benefit that can be attributable to the actions of another person or some impersonal (e.g., God, nature) sources (Emmons \& Shelton, 2002). Grateful feelings can be attended to and contemplated individually - and this has been formalized into an exercise where people report their daily experiences in a journal (Emmons \& McCullough, 2003). Additionally, the experience of gratitude can be communicated to the benefactor - and this has been formalized 
into an exercise where people write and deliver a letter of thankfulness (Seligman, Steen, Park, \& Peterson, 2005).

The interpersonal expression of gratitude is of particular interest for the science of well-being. In addition to personal benefits such as greater life satisfaction and fewer depressive symptoms, sharing grateful feelings offers relational benefits, promoting close relationship formation and maintenance (Algoe, Haidt, \& Gable, 2008; Lambert \& Fincham, 2011; Lambert et al., 2010). The presence of satisfying, meaningful social relationships has been shown to be the most robust predictor of whether or not someone can be classified as "very happy" (Diener \& Seligman, 2002). Sharing grateful feelings appears to be one way to strengthen and nurture social relationships.

Despite studies that document the efficacy of gratitude interventions, whether focused on personal experiences or the behavioral expression (Emmons \& McCullough, 2003; Lambert et al., 2010; Toepfer, Cichy, \& Peters, 2012), little is known how these activities are self-initiated in everyday life (Kaczmarek et al., 2013; Parks et al., 2012).

\subsection{Underlying motivations for gratitude interventions}

When people are given an opportunity to begin a gratitude intervention on their own, their intentions and actual behavior can be predicted by components of the theory of planned behavior (TPB) - beliefs about the likely consequences of behavior (utility beliefs), beliefs about others' expectations of the behavior (social norm beliefs), and beliefs about being able to handle the challenges inherent in starting and maintaining an intervention (self-control beliefs) (Ajzen, 1991; Kaczmarek, Kashdan, et al., 2014). To date, the only study that explored dissimilarities in belief systems across various positive psychological interventions was conducted with a sample of acutely suicidal psychiatric inpatients (Huffman et al., 2014). Huffman and colleagues found that out of 9 interventions, the two most efficacious were writing a gratitude letter and gratitude journaling, respectively. Interestingly, writing a gratitude letter was ranked as one of the three most difficult interventions to complete, whereas gratitude journaling was ranked as one of the two easiest interventions to complete. Difficulties associated with the gratitude letter were echoed in the feedback session as "negative comments focused on feeling too overwhelmed to complete the writing portion or to carry out an activity requiring interpersonal engagement". These findings suggest that utility and selfcontrol beliefs will be lower for the gratitude letter compared to gratitude journaling.

As further evidence for this hypothesis, theorists have argued that the psychological benefits of expressing gratitude to another person often comingle with negative outcomes (Wood, Froh, \& Geraghty, 2010). Being thankful towards other people means that a person is dependent on other people for their well-being and this sense of vulnerability can be viewed as uncomfortable (Kashdan, Mishra, Breen, \& Froh, 2009). These emotional costs, however, are often lower for people who are more grateful and by definition, biased toward perceiving help as beneficial (Wood, Maltby, Stewart, Linley, \& Joseph, 2008). Thus, the expression of gratitude may be related to stronger social bonds at the expense of personal well-being (Wood et al., 2010). Taken together, the psychological costs of writing gratitude letters are greater than gratitude journaling and these costs might translate into (low utility and self-control) beliefs that affect self-initiation.

\subsection{Current study}

By contrasting gratitude letters (interpersonal) with gratitude journals (individual), we sought to explore differences in two of the most efficacious positive psychological interventions (Huffman et al., 2014; Seligman et al., 2005). Using the theory of planned behavior (Ajzen, 1991), we explored potential differences in motivations for each of these interventions that in turn, influenced self-initiation and for those that took part, completion. Based on prior research, we hypothesized that people would have lower utility and self-control beliefs to write gratitude letters compared to journals.

Happiness seekers are a heterogeneous population and preintervention levels of targeted outcomes might differ and influence decision-making (Parks et al., 2012). To date, no study has examined whether individual differences in the threshold for experiencing gratitude influences the self-initiation and completion of gratitude interventions. As a secondary aim, we expected dispositional gratitude to be positively related to each TPB component (utility, self-control, and social norm beliefs). Finally, these motivational beliefs were expected to influence the self-initiation and completion of gratitude interventions.

\section{Method}

\subsection{Participants}

Participants were 904 undergraduates (75.6\% female) between the ages 18 and 50 years $(M=20.54, S D=2.49)$. Groups of students were approached before classes by experimenters and invited to a study about well-being. Those who volunteered constituted 93.38\% (response-rate) of 968 students who were initially approached. Volunteers remained anonymous and were not offered incentives. Missing data $(0.61 \%)$ were determined to be random via Little's test, $\chi^{2}(566)=555.49, p=.61$, and were imputed using Expectation-Maximization algorithm (Enders, 2001) in SPSS 21. Participants who did not report their sex $(n=19)$ were excluded from analysis. Written informed consent was obtained from each participant.

\subsection{Procedure}

Participants received leaflets with a description of a gratitude intervention - random assignment based on randomizer.org. Subsequently, participants reported their utility beliefs, social norm beliefs, and self-control beliefs regarding this intervention. They were informed that if they wanted to try out this intervention they should enter a dedicated website with instructions within the next seven days. Following that, behavioral intentions towards the intervention were measured.

Half of the participants were randomly assigned to a gratitude journal and the remaining to the gratitude letter intervention. All participants received the following information: "In recent years, research in psychology has established that performing certain activities can result in increased well-being and happiness." Following this, they were given intervention specific information.

For the gratitude letter:

"One of such activities is the 'gratitude letter'. In this activity you write a letter to someone to express your gratitude. You type this letter using a dedicated website and send it over e-mail or traditional post, or hand it in personally. The whole intervention involves writing three gratitude letters with weekly intervals."

After visiting the website they read this instruction:

"There are many things in our lives, both large and small, that we might be grateful about. Write a brief letter to someone whom you would like to thank. After you finish this survey, 
please send the letter to the addressee using e-mail, traditional post, or hand it in personally."

Participants composed letters in an online entry box. Before completion, they were requested to copy the letter to a webmail client to send it to their benefactors.

For the gratitude journal:

"One of such activities is the 'gratitude journal'. In this activity you write down up to five things in the past week that you are grateful for. You keep this journal using a dedicated website. The whole intervention involves writing three gratitude journal entries with weekly intervals."

\section{After visiting the website they read this instruction:}

"There are many things in our lives, both large and small, that we might be grateful about. Think back over the past week and write down on the lines below up to five things in your life that you are grateful for".

Participants were given seven days to start the intervention, and asked to write at least one letter or one journal entry (depending on condition) weekly. This resulted in an intervention that lasted up to three weeks.

Using a word processor to write gratitude letters and journals provides a methodological advantage over hand-written letters and journal entries because we could confirm that participants actually completed the tasks (Toepfer et al., 2012). At recruitment, participants received an invitation with personal codes to access the intervention website which allowed them to be anonymously tracked throughout the study. To increase commitment, participants were asked to indicate time and place of their next intervention visit at the end of each entry (Ajzen, Czasch, \& Flood, 2009).

\subsection{Measures}

We used four scales to measure utility, social norm, and selfcontrol beliefs, as well as behavioral intentions fitting with theories of planned behavior (Francis et al., 2004) and validated in prior studies (Kaczmarek, Kashdan, et al., 2014).

Utility beliefs, or attitudes about likely consequences of the gratitude intervention, were assessed with three 7-point bipolar evaluative adjective scales: "unpleasant-pleasant", "bad-good", and "useless-useful" ( $\alpha=.82)$.

Social norm beliefs, or beliefs about what others think about participating in the intervention, were assessed with three items about the expectations of important or valued others, e.g., "Most people who matter to me would approve my doing this intervention." Participants responded to items on a 7-point scale from 1 = "completely disagree" to 7 = "completely agree" $(\alpha=.89)$.

Self-control beliefs, or beliefs about being able to effectively cope and handle the exercises, were measured with three items about the feasibility of the intervention and the effort it would require, e.g., "Performing this intervention would be very easy for me." Participants responded to items on 7-point scale from 1 = "completely disagree" to 7 = "completely agree" $(\alpha=.93)$.

Behavioral intentions were assessed with six items about specific actions in the intervention. Preceded by the phrase "I intend to..." items included the following actions: "enter the intervention website", "read information from the website", "learn more about this activity". Participants responded to items on 7-point scale from 1 = "completely disagree" to 7 = "completely agree" $(\alpha=.96)$.

Dispositional gratitude was measured with the Gratitude Questionnaire-6 (McCullough et al., 2002) that requires answers on a scale from $1=$ "strongly disagree" to 7 "strongly agree" to six items, e.g., "I have so much in my life to be thankful for" $(\alpha=.75)$.

\subsection{Analytical strategy}

We used structural equation modeling with mPlus 7.12 (Muthén \& Muthén, 2012) to test whether behavior was predicted by intentions, intentions by motivational beliefs, motivational beliefs by dispositional gratitude, and motivational beliefs and gratitude disposition by sex and the type of activity (journal vs letter). Additionally, we controlled whether type of intervention and sex predicted intentions over motivational beliefs (Ajzen, 2011). The weighted least-square with mean and variance correction estimator (WLSMV) was used to evaluate fit of the structural model with binary outcomes (i.e., did the person self-initiate the gratitude intervention?) (Muthén \& Muthén, 2012). We calculated RMSEA, the recommended fit index for the WLSMV estimator with values $<.06$ indicating good fit and CFI with the cut-off value above .90 (Bentler, 1990). Bias-corrected bootstrapping with 10,000 samples was used to test indirect effects. Bootstrapping produces point estimates and confidence intervals $(\mathrm{CI})$ for the indirect effects. Significant indirect effects were indicated by confidence intervals that do not include zero.

\section{Results}

Descriptive statistics and inter-correlations are presented in Table 1 . In our sample, 50 participants completed the first day activity ( 37 for journal, 13 for letter) and 10 of them continued until the third week ( 7 for journal, 3 for letter). The hypothesized structural model depicting differences in the underlying motivations of the gratitude letter and gratitude journal is presented in Fig. 1. This model fit the empirical data well, $\chi^{2}(260)=648.34, p<.01$, RMSEA $=.04,90 \% \mathrm{CI}[.04, .05], \mathrm{CFI}=.94$. Intervention type had no effect on utility beliefs, $b=-.05, p>.05$, or social norm beliefs, $b=-.04, p>.05$. Participant sex had no significant effect on social norm beliefs, $b=.04, p>.05$. Inclusion of these paths had no effect on the model fit, $\Delta \chi^{2}(3)=4.65, p>.05$, thus they were removed.

In the model, intention predicted the behaviors and was predicted by motivational beliefs, intervention type, and sex of the recipient. Supporting our hypothesis, individuals who were offered the opportunity to write gratitude letters maintained lower selfcontrol beliefs than those offered gratitude journaling. Noteworthy, the type of intervention was not related to utility or social norm beliefs. More grateful individuals endorsed higher levels of each motivational belief. Women endorsed stronger utility beliefs but less self-control over the intervention.

Intervention type had a significant total effect on the completion of the intervention, $b=-0.136,99 \% \mathrm{CI}[-0.215,-0.063]$, with negative coefficients indicative of a lower probability of completion for the gratitude letter compared to the gratitude journal. This total effect resulted from two indirect effects (1) through selfcontrol beliefs, behavioral intention, and likelihood of starting the gratitude intervention, $b=-0.126,99 \% \mathrm{CI}[-0.206,-0.054]$ and (2) mediated by intention and the likelihood of self-initiation, $b=-0.010,95 \% \mathrm{CI}[-0.022,-0.001]$.

Individuals with high dispositional gratitude were more likely to complete the intervention, $b=0.133,99 \% \mathrm{CI}[0.082,0.178]$. This total effect comprised indirect effects operating through utility beliefs, $b=0.097,99 \% \mathrm{CI}[0.055,0.151]$, social norm beliefs, $b=0.022$, $99 \% \mathrm{CI}[0.007,0.042]$, and self-control beliefs, $b=0.011,99 \%$ $\mathrm{CI}[0.002,0.024]$. Women were more likely to complete the intervention as indicated by the total effect, $b=0.167,99 \% \mathrm{CI}[0.081,0.027]$.

\section{Discussion}

This is one of several recent studies that have moved beyond the efficacy of gratitude interventions to understand 
Table 1

Descriptive statistics and inter-correlations among study variables.

\begin{tabular}{|c|c|c|c|c|c|c|}
\hline & 1 & 2 & 3 & 4 & 5 & 6 \\
\hline \multicolumn{7}{|l|}{ 1. Utility beliefs } \\
\hline 2. Social norm beliefs & $.46^{* *}$ & & & & & \\
\hline 3. Self-control beliefs & $.17^{* *}$ & $.07^{*}$ & & & & \\
\hline 4. Intention & $.48^{* *}$ & $.38^{* *}$ & $.17^{* *}$ & & & \\
\hline 5. Dispositional gratitude & $.36^{* *}$ & $.21^{* *}$ & $.26^{* *}$ & $.24^{* *}$ & & \\
\hline 6. Age & .01 & .01 & .04 & .06 & .00 & \\
\hline 7. Sex & $.15^{* *}$ & $.08^{*}$ & $-.08^{*}$ & $.18^{* *}$ & $.15^{* *}$ & -.05 \\
\hline 8. Intervention type & -.04 & -.04 & $-.14^{* * *}$ & $-.16^{* *}$ & -.01 & -.01 \\
\hline 9. Behavior - first entry & $.19^{* *}$ & .04 & $.08^{*}$ & $.23^{* *}$ & $.07^{*}$ & .03 \\
\hline 10. Behavior - last entry & $.10^{* *}$ & -.01 & -.01 & $.10^{* *}$ & .03 & .03 \\
\hline$M$ & 13.97 & 14.62 & 13.08 & 23.88 & 31.17 & 20.54 \\
\hline$S D$ & 3.58 & 3.42 & 4.37 & 9.65 & 5.42 & 2.49 \\
\hline
\end{tabular}

Note. Intervention type coded as $0=$ gratitude journal, $1=$ gratitude letter. Sex coded as $0=$ man, $1=$ woman.

${ }^{*} p<.05$.

** $p<.01$.

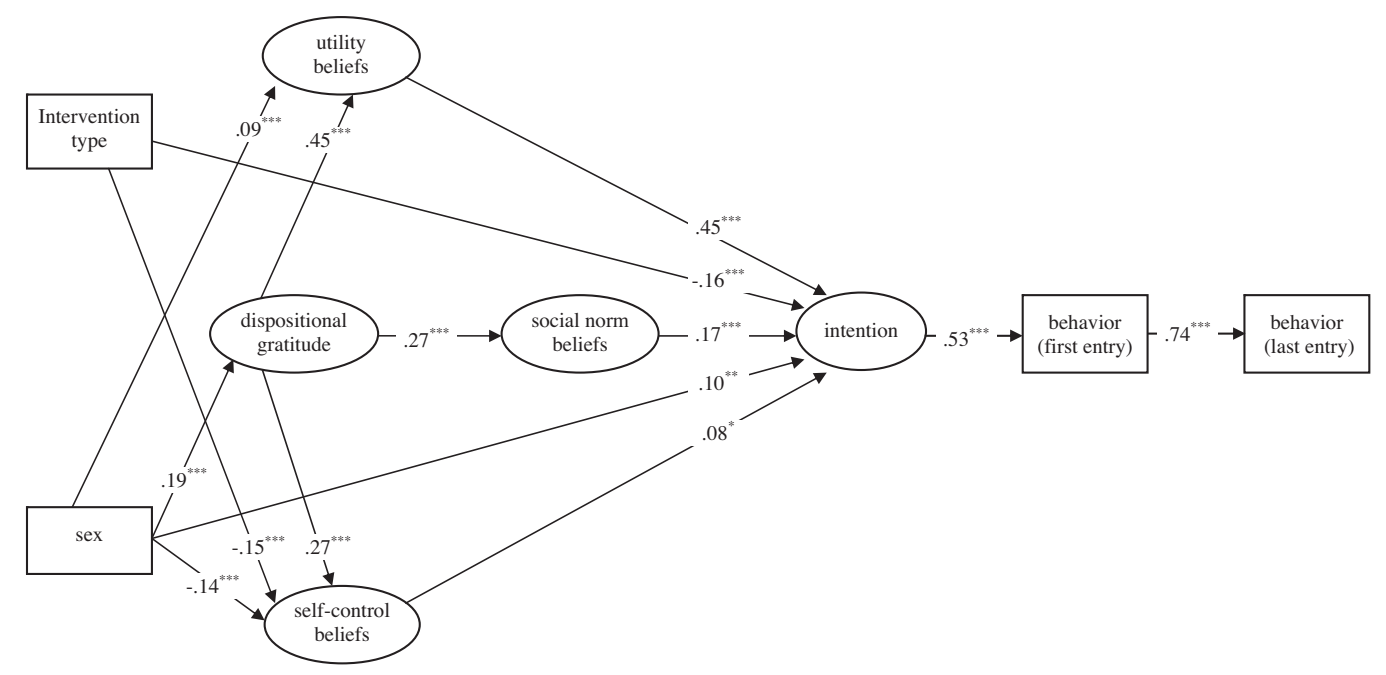

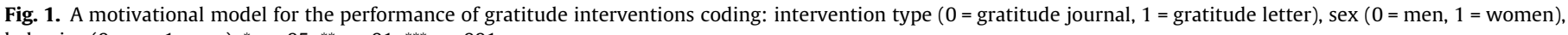
behavior $(0=$ no, 1 = yes $) .{ }^{*} p<.05,{ }^{* *} p<.01,{ }^{* * *} p<.001$.

who self-initiates them in everyday life (Kaczmarek et al., 2013; Parks et al., 2012). Our findings point out the importance of this approach to understanding positive psychological interventions given an opportunity actually start an intervention on their own, only $5.6 \%$ of individual do so. Despite the impressive efficacy of gratitude interventions to increase well-being (Huffman et al., 2014; Wood et al., 2010), change will only be elicited if people can be motivated to take the first step and experiment with new behavior strategies. From this vantage point, we explored several individual difference factors that might influence selfchange.

Upon giving 904 college students the option to take part in a three-week long intervention, we discovered a pattern of distinct motivations for who started and completed a gratitude journal versus a gratitude letter to a specific benefactor. Compared to the gratitude journal, writing a gratitude letter was less likely to be completed because it was perceived as difficult to complete. We also found evidence that people who are already inclined towards gratitude (disposition) were more likely to initiate gratitude interventions because of greater expected benefits, ease, and social acceptance toward their behavior. Our findings corroborate prior research suggesting that gratitude letters are viewed as a difficult activity compared to journaling (Huffman et al., 2014), and extend this work by revealing the importance of pre-intervention beliefs and individual differences.
Prior research suggests that writing gratitude journals has a more enduring impact on well-being whereas the interpersonal expression has a more intense, short-lived impact (Seligman et al., 2005). The psychological difficulties of composing a gratitude letter appear to outweigh the benefits of the easier, more efficient, and efficacious nature of regularly recording feelings of appreciation for people and prior events in a journal. Thus, there is correspondence between people's expectations prior to gratitude interventions and the actual effectiveness of these interventions.

In prior work, we found that women are more likely to participate in gratitude interventions (Kaczmarek et al., 2013). Extending these findings, we found that women were more likely to expect positive responses from others in reference to taking part in gratitude activities (social norm beliefs), and this effect was a function of their greater dispositional gratitude. Women were also more likely to view the gratitude intervention as useful; however, they also doubted their self-efficacy for the intervention compared to men. Importantly, the psychological benefits of gratitude interventions for women could not be fully explained by their tendency to be more grateful (Kashdan et al., 2009). These findings offer insight into mechanisms behind motivation of women to initiate and complete gratitude interventions.

This is the fourth study where we found that TPB offered utility as an explanatory framework for people's motivation to initiate positive psychological interventions (Kaczmarek et al., 2013; 
Kaczmarek, Goodman, et al., 2014; Kaczmarek, Kashdan, et al., 2014). Two novel insights for the model arose from the current study. First, findings suggested that of the components, self-control beliefs are a significant, albeit weak predictor of gratitude interventions. Previous studies on gratitude interventions also indicated that self-control beliefs are the weakest (Kaczmarek et al., 2013) or non-significant in predicting gratitude related intervention intentions (Kaczmarek, Goodman, et al., 2014). This suggests that although the gratitude interventions varied in difficulty, they can be considered much more feasible than complex healthy initiatives (Madden, Ellen, \& Ajzen, 1992). Second, the background variables (intervention type and sex) had a significant direct effect on intentions to start the intervention that were not mediated by motivational beliefs. TPB posits that the motivational beliefs completely mediate background and behavioral outcomes (Ajzen, 1991, 2011). Our research program suggests that this notion might be antiquated and there should be more emphasis on additional mediators such as past behaviors (Norman \& Cooper, 2011) or sense of autonomy support (Kor \& Mullan, 2011).

There are several limitations of this study. First, we used a student sample. Although this makes our study compatible with efficacy studies with student samples (e.g., Emmons \& McCullough, 2003), it remains to be seen whether the same model is valid for less educated peers or other age cohorts. In a previous study the validity of the motivational model was confirmed using data of a community sample (Kaczmarek, Kashdan, et al., 2014). Second, this study did not account for intervention outcomes, such as postintervention levels of gratefulness and well-being. Prior research suggests that motivated individuals reap more benefits from positive psychological interventions (Lyubomirsky, Dickerhoof, Boehm, \& Sheldon, 2011) and increased utility beliefs amplify gains (Layous, Nelson, \& Lyubomirsky, 2012). Future studies should use methodology that extends beyond intervention initiation and completion to the psychological, social, and physical health gains.

Our results have practical implications. For instance, gratitude journals might be more appropriate to increase well-being as they are more likely to be embraced by recipients. Attempts to help participants in increasing their self-efficacy regarding such straightforward interventions (e.g., through the provision of instructional support) may back-fire by suppressing autonomy and thus the desirability to take part (Kaczmarek, Goodman, et al., 2014). This study also provided evidence that when disseminating gratitude interventions we can expect certain groups of individuals to be repelled from our message. It is ironic, yet now understood, that a lower self-initiative to cultivate gratitude is probable among those individuals who are already experiencing less frequent, intense, and enduring gratitude (and chronically ungrateful men seem to be the hardest group to intervene with; Kashdan et al., 2009). Although it is not imperative to pursue universal increases in gratitude, in future studies, we should attempt to learn more about these subgroups and their perspective on gratitude. Finally, this study indicated that only a small fraction of individuals faced with a gratitude intervention opportunity complete this intervention. Volunteers' initial interest might have waned by the lack of immediate gratification as their attention returned to daily routines and obligations. It might be worthwhile to use reminder e-mails to sustain their interest and facilitate self-management of interventions.

One of the strengths of our study is that we developed a brief, informative procedure that proved effective in obtaining a high response rate (93.4\%). This allowed us to test the robustness of our model with a heterogeneous student sample of happiness seekers (high intenders and actual doers) and individuals with low motivation and intention toward starting gratitude interventions. Our approach supplements previous studies that used selfselected happiness seekers (Parks et al., 2012) or clinical groups
(Huffman et al., 2014), and balanced self-report data with behavioral observations (online activity). Third, with an experimental design (randomizing into different interventions), we could explore how the predictors of one gratitude intervention are not necessarily the same for another. Fourth, our approach had ecological validity as students were recruited during their daily educational routines, and they planned and carried out the intervention on their own in natural settings.

The current project is another step towards a better understanding of different gratitude interventions. Our motivationfocused approach complements a growing literature concerned with the variety, efficacy, and effectiveness of positive psychological interventions (Bolier et al., 2013). What works in the laboratory when you pay participants and assign them to interventions masks the complexity of trying to elicit psychological change in the realworld.

\section{Acknowledgements}

The authors would like to thank Aleksandra Krajczewska, Michał Misiak, and Jakub Szwedo for assisting with participant recruitment.

\section{References}

Ajzen, I. (1991). The theory of planned behavior. Organizational Behavior and Human Decision Processes, 50, 179-211.

Ajzen, I. (2011). The theory of planned behavior: Reactions and reflections. Psychology \&' Health, 26, 1113-1127.

Ajzen, I. Czasch, C. \& Flood, M. G. (2009). From intentions to behavior: Implementation intention, commitment, and conscientiousness. Journal of Applied Social Psychology, 39, 1356-1372.

Algoe, S. B., Haidt, J., \& Gable, S. L. (2008). Beyond reciprocity: Gratitude and relationships in everyday life. Emotion, 8, 425-429.

Bentler, P. M. (1990). Comparative fit indexes in structural models. Psychological Bulletin, 107, 238-246.

Bolier, L., Haverman, M., Westerhof, G. J., Riper, H., Smit, F., \& Bohlmeijer, E. (2013). Positive psychology interventions: A meta-analysis of randomized controlled studies. BMC Public Health, 13, 119.

Diener, E., \& Seligman, M. E. (2002). Very happy people. Psychological Science, 13(1), $81-84$.

Enders, C. K. (2001). A primer on maximum likelihood algorithms available for use with missing data. Structural Equation Modeling, 8(1), 128-141.

Emmons, R. A., \& Shelton, C. M. (2002). Gratitude and the science of positive psychology. In C. R. Snyder \& S. J. Lopez (Eds.), Handbook of positive psychology (pp. 459-471). New York: Oxford University Press.

Emmons, R. A., \& McCullough, M. E. (2003). Counting blessings versus burdens: An experimental investigation of gratitude and subjective well-being in daily life. Journal of Personality and Social Psychology, 84, 377-389.

Francis, J. J., Eccles, M. P., Johnston, M., Walker, A. E., Grimshaw, J. M., Foy, R., et al. (2004). Constructing questionnaires based on the theory of planned behaviour. A manual for health services researchers. UK: Centre for Health Services Research, University of Newcastle upon Tyne.

Huffman, J. C., DuBois, C. M., Healy, B. C., Boehm, J. K., Kashdan, T. B., Celano, C. M., et al. (2014). Feasibility and utility of positive psychology exercises for suicidal inpatients. General Hospital Psychiatry, 36(1), 88-94.

Kaczmarek, L. D., Goodman, F. R., Drążkowski, D., Kashdan, T. B., Połatyńska, K., \& Komorek, J. (2014). Instructional support decreases desirability and initiation of a gratitude intervention. Personality and Individual Differences, 64, 89-93.

Kaczmarek, L. D., Kashdan, T., Drążkowski, D., Bujacz, A., \& Goodman, F. (2014). Why do greater curiosity and fewer depressive symptoms predict gratitude intervention use? Utility beliefs, social norm beliefs, and perceived selfcontrol. Personality and Individual Differences, 66, 165-170.

Kaczmarek, L. D., Kashdan, T. B., Kleiman, E., Bączkowski, B., Enko, B., Siebers, A., et al. (2013). Who self-initiates gratitude interventions in daily life? An examination of intentions, curiosity, depressive symptoms, and life satisfaction. Personality and Individual Differences, 55, 805-810.

Kashdan, T. B., Mishra, A., Breen, W. E., \& Froh, J. J. (2009). Gender differences in gratitude: Examining appraisals, narratives, the willingness to express emotions, and changes in psychological needs. Journal of Personality, 77(3), $691-730$.

Kor, K. \& Mullan, B. A. (2011). Sleep hygiene behaviours: An application of the theory of planned behaviour and the investigation of perceived autonomy support, past behaviour and response inhibition. Psychology E Health, 26(9), $1208-1224$

Lambert, N. M., Clark, M. S., Durtschi, J., Fincham, F. D., \& Graham, S. M. (2010). Benefits of expressing gratitude expressing gratitude to a partner changes one's view of the relationship. Psychological Science, 21(4), 574-580. 
Lambert, N. M., \& Fincham, F. D. (2011). Expressing gratitude to a partner leads to more relationship maintenance behavior. Emotion, 11(1), 52.

Layous, K., Nelson, S. K., \& Lyubomirsky, S. (2012). What is the optimal way to deliver a positive activity intervention? The case of writing about one's best possible selves. Journal of Happiness Studies, 14, 635-654.

Lyubomirsky, S., Dickerhoof, R., Boehm, J. K., \& Sheldon, K. M. (2011). Becoming happier takes both a will and a proper way: An experimental longitudinal intervention to boost well-being. Emotion, 11, 391-402.

Lyubomirsky, S., \& Layous, K. (2013). How do simple positive activities increase well-being? Current Directions in Psychological Science, 22(1), 57-62.

Madden, T. J., Ellen, P. S., \& Ajzen, I. (1992). A comparison of the theory of planned behavior and the theory of reasoned action. Personality and Social Psychology Bulletin, 18, 3-9.

McCullough, M. E., Emmons, R. A., \& Tsang, J. A. (2002). The grateful disposition: A conceptual and empirical topography. Journal of Personality and Social Psychology, 82(1), 112-127.

Muthén, L. K., \& Muthén, B. O. (2012). Mplus user's guide (7th ed.). Los Angeles, CA: Muthén \& Muthén.

Norman, P. \& Cooper, Y. (2011). The theory of planned behaviour and breast selfexamination: Assessing the impact of past behaviour, context stability and habit strength. Psychology \& Health, 26, 1156-1172.
Parks, A. C., Della Porta, M. D., Pierce, R. S., Zilca, R., \& Lyubomirsky, S. (2012) Pursuing happiness in everyday life: The characteristics and behaviors of online happiness seekers. Emotion, 12(6), 1222-1234.

Seligman, M. E. P., Steen, T. A., Park, N., \& Peterson, C. (2005). Positive psychology progress. Empirical validation of interventions. American Psychologist, 60, 410-421.

Sheldon, K. M., \& Lyubomirsky, S. (2007). Is it possible to become happier? (And if so, how?). Social and Personality Psychology Compass, 1(1), 129-145.

Toepfer, S. M., Cichy, K., \& Peters, P. (2012). Letters of gratitude: Further evidence for author benefits. Journal of Happiness Studies, 13(1), 187-201.

Toepfer, S. M., \& Walker, K. (2009). Letters of gratitude: Improving well-being through expressive writing. Journal of Writing Research, 1(3), 181-198.

Wood, A. M., Froh, J. J., \& Geraghty, A. W. (2010). Gratitude and well-being: A review and theoretical integration. Clinical Psychology Review, 30(7), 890-905.

Wood, A. M., Maltby, J., Stewart, N., Linley, P. A., \& Joseph, S. (2008). A socialcognitive model of trait and state levels of gratitude. Emotion, 8(2), 281. 